\title{
Research and Practice of Innovative Talents based on the Internet of Things Competition Mechanism
}

\author{
Baoling Qin \\ Information Educational Technology Center, Foshan University \\ Guangdong Foshan 52800, China
}

\begin{abstract}
The essay introduces the significance, method and application effects of innovative talents based on The Internet of things competitions. Analysis begins with the reform of teaching model on a basis of The Internet of things competition mechanism. By creating a platform of The Internet of things competitions, we integrate education resources, set up a mechanism of innovative talents training, and create an innovative platform and environment for teachers and students. Moreover, we promote the reform of teaching model, improve the quality of higher education and cultivate students' open mind and innovative ability. Meanwhile, the essay makes a deep analysis and summary on some exiting problems in talents cultivation and puts forward practical and prospective solutions.
\end{abstract}

Keywords-The Internet of things; Competition mechanism; Innovative talents; Platform

\section{INTRODUCTION}

With the relentless march of information technology and its applications, especially the applications of Internet + in all areas, competitions between industries and even between nations have been aggravated. In other words, it is a scramble of technology talents. Since universities are the birthplace of talents, the society's basic requirement on higher education's quality is to improve education quality and to cultivate more innovative talents. Though The Internet of things engineering is a new major, the objective in new engineering personnel training is high standards, especially training of various aspects including the ability of engineering practice and innovation. How to develop those ability? We mainly start with basic innovation like college students' thoughts and this basic Quality Education has to find out the answers and results from teaching cultivation model and innovative platform [1].

In recent years, my university's The Internet of things engineering department of Electronic Information Engineering school starts with innovative teaching models based on The Internet of things competitions mechanism, have a further research on the theory and approaches on innovative mechanism and apply them into practice. We also encourage students to participate in various innovative activities, take them into our teachers' scientific teams and organize them to take part in innovative competitions from universities, Guangdong province and even the nation. Examples are programming contests, information work contest and national "Blue Bridge Up" competition. On one hand, students will increase their interest in curriculum, improve their manual dexterity and develop the innovative thinking. On the other hand, based upon The Internet of things competitions mechanism, we set up an innovative talents platform, which adopts a teaching mode that senior students lead the junior and they are instructed by teachers, to build a new and circular teaching mode. In this model, students or teachers apply for the project approving and funds, carry out the project, sum it up, take part in works competitions and draw a conclusion after contests.

This implement of new teaching method improves students engineering practical ability and innovative thinking as well as wining honor for students and schools in the competitions. Moreover, it contributes to improve the reform of innovative education for teachers and enhances their practical ability in teaching. Students' doing project design and development work in the lab increases the utilization rate of experimental devices, improves their thinking and practical ability, and enhances their communication and cooperation ability. Students with different interest and different majors cooperate to finish the project, which helps to let their strength shine. It also provides many technical support for project research and helps to finish the index.

\section{RESEARCH ON TEACHING MODE REFORM UNDER THE IOT COMPETITION MECHANISM}

The goal of Double First-Class Initiative is to ask universities to change current traditional teaching mode and to cultivate students with innovative ideas and good manual dexterity.

According to Internet information, Iot major is a new engineering major which is vastly applied and is put forward related to practice in universities. The traditional engineering teaching mode is theory teaching + practice teaching. Now, we have entered an era of Internet + . As many theory and practice teaching no longer meets the need of new engineering teaching, we have to change current teaching method, and to adopt an innovative talents cultivation teaching mode based on Iot competition mechanism, whose core is project contests. We set up teams, put the applied projects into use, apply for funds, carry out the project and sum it up. Then, we hold a school rating and choose the superior one to participate in competitions of Foshan city. In the end, we draw a conclusion of every part and find out advantages and disadvantages. The project is instructed by related curricular teachers and the team is made up of students. Senior students cooperate with junior 
ones to make an innovative project, which helps create a new, stable and circular teaching mechanism.

We change the old teaching methods, and set up a studentsbased teaching platform, through which we build a teaching mode of innovative talents education. With this mode, more students can win prizes in different Iot competitions. It wins the honor of students and school and promotes the teaching reform of theory and practice innovation. Students' making designs and development in the lab ensures the devices of the lab are used well, improves their manual and creative ability, and enhances their cooperation and communication [2]. Moreover, since students of different majors join in the project, they can show their advantages to complete the project in a better way.

\section{RESEARCH ON INNOVATIVE PERSONNEL TRAINING MECHANISM}

\section{A. Research on mechanism construction platform}

In science and engineering universities, innovative talents training platform requires not only the conditions like the lab and practice base, but also system construction and innovation of educational ideas, teaching methods and the forms. It sets a goal of innovative talents training as the essence, establishes innovative teaching platform and builds up a theory whose core is various innovative ability training. In order to build a platform, the following 4 principles need to be carried out.

\section{1) Adhere to students' subjectivity}

Students are main body in innovative platform, such as organization, system management, operation mode and practice content, otherwise, the platform will run out of power. Every innovative practice adheres to "3 independence"--organization, design and completion. Therefore, students can have innovative learning, studying and development more actively and a good innovative environment is born.

\section{2) Adhere to teachers' guidance}

Teachers mainly play an instructive role in the platform. They help students select the projects, apply for funds and offer technical guidance. The purposes are to help them find out the key frontier technical research, lead them to cooperate with each other and play their advantages in the platform, let them put innovative ideas into practice boldly, sum up innovation and push forward the new theory.

\section{3) Adhere to students' individual training}

Students' individual training is one characteristic of the platform, which is the main motivation and support for students to study independently and carry out innovative practice. When teachers give guidance to students, they should be good at finding students with this strength and help them to play their advantages in practice. Teachers should also build up an innovative teaching mode with various characteristics so that they can meet students' need to innovation.

\section{4) Adhere to students' independent innovation}

Students' independence of innovation is the core of the platform. Every activities should be put forward with it and should encourage students with the goal of "Independent study, mutual cooperation, innovation". When teachers give instruction, they should create a teaching practice space of "Freedom and Open" to inspire their innovative thinking and to release their innovation enthusiasm in a maximum extent.

\section{B. Mechanism construction principle}

\section{1) Sharing of innovative platform resources}

Teaching experimental resources in science and engineering are in great investment such as practice base and practice equipment. The former can absorb social capital and adopt a co-construction, sharing and win-win mechanism. For the latter, we make full use of existing practice equipment when building the innovative platform. We also adopt an "Integration and Deployment" approach in similar majors' experimental equipment and push forward the innovative platform in a planned, scheduled and high standard way. In addition, we share platform resources of teaching practice to avoid repetition and waste of resources so that we can spend limited fund on key devices. We adopt cross setting in teaching practice platform, improve the utilization rate of teaching devices resources so complete hardware platform devices can provide a good scientific environment for innovative talents training.

2) Establishment of innovation platform and talents system

Practice base and laboratories are essential infrastructures in science and engineering. Through information platform, we have integrated management, make reservation system, and set up certificate system and we also open it for students to do scientific training. Students can use the platform experiment equipment according to the actual needs of their own projects and arrange the appointment of equipment and teachers flexibly. The experiment content is centered on project and our principle is "Teaching in accordance with the aptitude of the students" and "The practical effects". Meanwhile, we decide the experiment content of open labs according to different levels of requirements. It encourages students to innovate experimental methods, explore experimental design ideas, innovate their thinking and participate in the practical solutions According to the cooperative mechanism of school enterprises, we, relying on the experimental base, build a platform for innovation and training, increase students' participation in various contests, perfect their knowledge structure and improve their innovative ability [3].

\section{3) Competition system adopted fro project mechanism}

The investment in scientific research is the material basis for the race results. The university and secondary school strongly encourage students to take part in various scientific research and technology activities and give the financial support to have the funds used in specific areas. Examples of the competitions are "CUMCM","Challenge Cup" and "Iot design competition". Students' works will be selected by school and eventually participate in the next round. We encourage students to participate in teachers projects like reforms of new engineering talents and teaching to increase their enthusiasm for innovation so that they can participate in 
scientific research training as soon as possible and can build up a foundation for future research [4]. Currently, Iot has also combined social forces to enable students to participate in practise of off-campus projects and jointly promote the training of innovative platform talents on the basis of mutual benefits.

\section{The implementation mode of mechanism construction}

Science and engineering universities set up all kinds of activity groups of science and technology and hold various technology innovation activities. Though the groups, students do the management and take part in competition in a competitive way. For example, in "Smart home management system" groups and "Intelligent industrial robot innovation design" group, the leader is one senior student with some experience and the body is students' independent management and independent learning, in which teachers simply offer help of coordination, direction and guidance [5].

My university strongly support all kinds of scientific research activities, especially all kinds of national, provincial, city competitions. We also make full use of training work before the innovation platform holds any competitions to create a good environment for participants. At the same time, we motivate them to join in teachers' team in the platform and let them receive scientific research training. The purposes are, with practise in the platform, to enable students look up for technology information, use the essay research, make science experiment plans under reference and summary, draw the summary of sample test analysis and experiment's results, learn to communicate, have contact with enterprises, help them solve technical problems, gain project, write the project application and to organize the implementation of the project.

\section{PRACTICAL RESULTS IN INNOVATIVE TALENTS TRAINING BASED ON COMPETITION}

In recent years, my university has promoted the development of constructing high level science and engineering, advocated "patent" for everyone, support innovation platform construction, and vigorously promoted the teaching mode reform, which strengthens the students' handson practical ability and cultivates students' creative thinking ability and the effect is remarkable.

In innovation platform project, each project has a guiding teacher to solve the difficulties students have encountered in the process of innovation project research. Teacher are enlightening guidance, and specific implementation is done by the students on their own. In this way, students have autonomy and independence in the process of project research and can improve the success rate at the same time. Over the past few years the Internet of things organizes the student to participate in national, provincial, municipal and other kinds of innovative and obtained some achievements, like "basket bridge cup software competition" and "Internet of things design competition". Some works won 1 national second prize and 2 third prize, 2 provincial first prize and 3 second-class, and 12 city-level awards. They have won a lot of honors for the school and improved school's reputation. Meanwhile it also promotes the reform of teaching ideas. For example, in the first half of 2017, 2016 iot professional students of Class 5 attend national da competition, in which 2 of them won the second prize of national work and 1 third prize in Guangdong province.

In the process of innovation, students do practice independently, from the design concept, to the project establishment, personnel organization and cooperation, technology application and integration, and implementation. To complete the project, students must make full use of the extracurricular time, such as evenings, weekends and holidays. Participation in innovative works requires students to keep improving. For instance, "Internet of things smart home" projects, team members have investigation into the factory, grasp first-hand information, design a variety of plans though looking up data, organize the discussion and debate and select the best design scheme in the end. In innovation activity, the students spend a lot of time, but also they learn a lot of new knowledge. At the same time, they build up the tough quality, cultivate their practical innovation ability so that it enhances their understanding on the Internet of things engineering curriculum knowledge architecture and increases their interest in the Internet of things.

At present, our school strongly encourage college students to participate in all kinds of "innovation competition" and "skill competition", advocate "all innovation, all patents" hing school measures, hoping through competition and their creations, they can absorb more experience and improve all kinds of ability. In a word, through the innovation platform, a lot of students have gained a lot after the competition and, learned a lot of new knowledge and new technology. Meanwhile they also see their own shortcomings, which has inspired many students to work harder to learn new knowledge and new technology to build a more solid foundation for later work.

\section{EXISTING PROBLEMS AND REFLECTION}

To build a basis for further reform in science and engineering innovative talents training in universities, and to set up a good platform of the new technical innovation teaching mode reform, in recent years, we establish an innovative talent training platform based on Internet of competition mechanism. In this platform, teaching achievements have achieved good results, but our school, after all, is a ordinary science and engineering university, with great difference from the domestic key universities. For example, the number of national awards is relatively small, so do prizes of scientific research and patent invention, the topic of the project is too simple, and the lack of frontier. This few aspects should be strengthened in future work, especially playing the strengths of other subjects, enhancing collaboration, such as machinery, electronics, automation, robotics to make breakthrough development. Under the school support, innovation platform based on Internet of competition mechanism plays an important role in promoting teaching reform, strengthening the students' practice ability and innovation ability training. Still some problems exist, for example, the process of innovation project and funding approval is cumbersome and complex, funds investment in innovation activities should raise. We should also strengthen the encouragement for students to go out of school, cultivation of their pragmatic entrepreneurial innovation ability and increase in their enthusiasm to local 
enterprises so that they can make greater contribution to the transformation and upgrading of local enterprises.

\section{SUMMARY}

Iot is the emerging major and everyone is in the exploration. There is no mature teaching modes, especially the innovative talent training nor there is few exploration and research in this field. The author with years of teaching research and practice in higher education sums up the idea and the mainstream of innovative talent training based on Internet of competition mechanism is of good study value and certain ground breaks, which are suitable for current higher education innovation personnel training and has remarkable achievements. Yet, some theories and ideas still need to be further excavated and improved.

\section{REFERENCES}

[1] BaoLing Qin. Application of modern information technology in teaching quality control in universities $[\mathrm{J}]$. China management informatization, 2016 (9):253-254.

[2] Baoling Qin. Analysis of basic teaching quality exploration and capacity training in the application of basic teaching database in colleges and universities [J]. Computer knowledge and technology, 2013(11):70547056 .

[3] Ming Li. Integration strategy, practical improvement of the quality assurance system of colleges and universities $[\mathrm{J}]$. China higher education, 2011(11):40-42.

[4] Wenjun Dong,Xinmin Huang. Theoretical considerations on the quality management of college teaching based on information technology [J]. Education and occupation, 2008(9):55-56.

[5] Lina Wang. Establishment and practice of teaching quality assessment system in higher education $[\mathrm{J}]$. China higher medicine education, 2008(9):53-54. 